\title{
Relative validity of a web-based food frequency questionnaire for Danish adolescents
}

Anne A. Bjerregaard ${ }^{1 *} \mathbb{D}$, Thorhallur I. Halldorsson ${ }^{1,2}$, Freja B. Kampmann ${ }^{3,4,5}$, Sjurdur F. Olsen ${ }^{1}$ and Inge Tetens ${ }^{6}$

\begin{abstract}
Background: With increased focus on dietary intake among youth and risk of diseases later in life, it is of importance, prior to assessing diet-disease relationships, to examine the validity of the dietary assessment tool. This study's objective was to evaluate the relative validity of a self-administered web-based FFQ among Danish children aged 12 to 15 years.

Methods: From a nested sub-cohort within the Danish National Birth Cohort, 124 adolescents participated. Four weeks after completion of the FFQ, adolescents were invited to complete three telephone-based 24HRs; administered 4 weeks apart. Mean or median intakes of nutrients and food groups estimated from the FFQ were compared with the mean of $3 \times 24 \mathrm{HRs}$. To assess the level of ranking we calculated the proportion of correctly classified into the same quartile, and the proportion of misclassified (into the opposite quartile). Spearman's correlation coefficients and de-attenuated coefficients were calculated to assess agreement between the FFQ and 24HRs.

Results: The mean percentage of all food groups, for adolescents classified into the same and opposite quartile was 35 and $7.5 \%$, respectively. Mean Spearman's correlation was 0.28 for food groups and 0.35 for nutrients, respectively. Adjustment for energy and within-person variation in the 24HRs had little effect on the magnitude of the correlations for food groups and nutrients. We found overestimation by the FFQ compared with the 24HRs for fish, fruits, vegetables, oils and dressing and underestimation by the FFQ for meat/poultry and sweets. Median intake of beverages, dairy, bread, cereals, the mean total energy and carbohydrate intake did not differ significantly between the two methods.

Conclusion: The relative validity of the FFQ compared with the 3×24HRs showed that the ranking ability differed across food groups and nutrients with best ranking for estimated intake of dairy, fruits, and oils and dressing. Larger variation was observed for fish, sweets and vegetables. For nutrients, the ranking ability was acceptable for fatty acids and iron. When evaluating estimates from the FFQ among Danish adolescents these findings should be considered.
\end{abstract}

Keywords: Dietary assessment, School-age children, Diet, Dietary intake, Cohort study, Food groups, Nutrients, Diet recall

\section{Background}

Dietary intake among adolescents has consistently been associated with later health and disease risk in adult life $[1,2]$. Diet-disease associations measured in adolescence are often based on dietary intake estimated from a food frequency questionnaire (FFQ) particularly in largescale studies [2-6]. The FFQ method is often self-administered which is more cost-effective, less intrusive, and less time-

\footnotetext{
* Correspondence: anne@ssi.dk

${ }^{1}$ Center for Fetal Programming, Department of Epidemiology Research,

Statens Serum Institut, Artillerivej 5, 2300 Copenhagen, Denmark

Full list of author information is available at the end of the article
}

consuming for the participants compared with other dietary assessment methods such as multiple 24-h recalls (24HR) and food records [7]. However, prior to assessing diet-disease relationships, the validity of the dietary assessment tool must be examined [8].

Validity refers to the degree to which an assessment method captures true dietary intake [9]. Such assessment requires comparison with 'a gold standard' method which, in reality, is rarely available. Therefore researchers are often left with the option of examining relative validity by comparing one dietary assessment method with another method that has a different error structure [10]. 
Although a $24 \mathrm{HR}$ relies on memory, as does the FFQ, 24HRs are common in relative validity studies using FFQs among adolescents [11, 12]. FFQs are in general considered suitable or valid for ranking adolescents at group level with correlation coefficients ranging from 0.2 to 0.8 [11-14]. In terms of what can be considered as acceptable validity in such studies, Cade et al. suggested a cut-off of 0.40 as an acceptable correlation [15]. However, such an approach has been criticised by others, as a correlation of 0.50 indicates that $75 \%$ of the variance in estimates is error, thus increasing the risk of misclassification in association studies [16]. Nevertheless, correlation coefficients are still the main statistical approach in validation studies which ensures the possibility for some comparison across studies. A recent meta-analysis found correlation coefficients above 0.40 for most nutrients in 16 validity studies comparing an FFQ to food record or 24HRs among 13- to 17-year-old adolescents [10]. However, high heterogeneity was also reported in validation studies with administration mode and recall interval as strongest contributors [10]. Other factors which potentially influence validity are the respondent's memory and ability to identify and quantify consumed foods $[17,18]$. In addition, compared with validation studies in adults, a higher degree of intrusion and omission among children has been demonstrated [19]. Thus, it is important to evaluate if an FFQ can assess dietary intake and rank adolescents in terms of energy, nutrient, and food intakes. To our knowledge, a web-based FFQ has not previously been validated among Danish adolescents. The aim of this study therefore was to evaluate the relative validity of a web-based FFQ using a nested sub-cohort of adolescents aged 12 to 15 years old, within the Danish National Birth Cohort (DNBC).

\section{Methods \\ Subjects}

The DNBC includes information from 101,042 pregnancies and is described in details elsewhere [20]. In brief, information on participants was recorded through telephone interviews in gestation weeks (GW) 12 and 30, and 6 and 18 months postpartum. Maternal diet was assessed in GW 25 using an extensive FFQ [20]. Additional available offspring data were collected at age 7 and 11.

Data for the present study were obtained in a nested sub-cohort within the DNBC called the Diabetes and Women's Health Study, which ran from May 2012 to April 2014 [21]. In a group of women who had had gestational diabetes (GDM) and a group of women who had had a normal pregnancy, insulin sensitivity, risk of type 2 diabetes, and risk of diabetes in offspring aged 915 years were investigated [21]. This sub-cohort provided an opportunity to invite adolescents between 12 to 15 years of age to participate in the validation study. The invited adolescents were offspring of women already in the DNBC cohort. These adolescents were all considered relatively healthy in terms of non-communicable diseases, and no exclusion criteria were applied.

\section{Design}

All offspring of mothers participating in the Diabetes and Women's Health Study were invited to fill out a web-based FFQ during their pre-planned clinical visit. After the clinic visit, 178 adolescents were asked to participate in the $24 \mathrm{HRs}$ by e-mail (45), phone (12) or hand-out at the clinic (121). Follow-up on the invitation was done by e-mail and by phone call approximately 7 days after the invitation was received and 7 days apart. The first 24HR was carried out 4 weeks after the FFQ followed by two recalls 4 weeks apart. Three nonconsecutive telephone-based 24HRs were conducted by four trained nutritionists, and each interview took approximately $25 \mathrm{~min}$. In order to make the $24 \mathrm{HRs}$ represent weekdays and weekends, a set of three different days were randomly designed. A set of 3 days was distributed to the participants, ensuring equal distribution of all 7 days of the week at group level. Participants were not informed beforehand as to which day the 24HR would be performed. They only received a mobile text message on the day the recall took place, to arrange a suitable time for the conversation. All participants automatically entered into a competition to win one of three Ipads.

\section{The food frequency questionnaire}

The web-based self-administered FFQ developed for this study was based on the validated youth/adolescent questionnaire (YAQ) from the Growing Up Today Study $[13,22]$ which is a follow-up study of children born to women in the Nurses' Health Study 2 (NHS-2). The YAQ was translated into Danish and modified to include typical Danish foods based on the reports National Danish Dietary Habits and Physical activity [23, 24]. The aim of modifying the YAQ was to make sure that the FFQ reflects Danish dietary patterns and thus intake of Danish foods and beverages. We previously evaluated the reproducibility of the FFQ and showed high concordance between two repeated measurements with the FFQ with a Spearman's correlation coefficient for energy of 0.78 [25].

The FFQ included 145 frequency questions on food items clustered into 8 food groups (number of food items in brackets): beverages (18), dairy (8), bread and cereals including butter on bread (14), spread on bread (14), cold and warm dishes (25), side dishes and condiments (18), fruits and vegetables (29), snacks and desserts (20). Frequency scales ranged from "did not drink/ consume the last month" to "2 times or more per day" 
or "4 times or more per day" and the recall period was 1 month. Portion sizes were predefined for dairy products (bowl), breakfast cereals (bowl), and beverages (glass/bottle), slides of bread, fruits (pc.), selected vegetables (pc.), and cake (pc.), whereas no portion size was given for the remaining items. Portion sizes were based on standard portions developed by the National Food Institute in Denmark [26]. Additional information on food allergy, other foods the participant may wish to avoid and any major changes in food habits during the last month was included in three open-end questions.

Before the FFQ, questions on age, gender, and selfreported height and weight were listed. Following the FFQ, questions on (number of questions in parenthesis); meal habits (15), physical activity (11) and puberty (6) were listed. Finally, the participants were asked to which degree they completed the questionnaire themselves or received help from an adult. Written instruction on how to complete the questionnaire was given at the beginning of the questionnaire together with short examples of answers. Time for filling in the FFQ was approximately 40 min. The FFQ was based on the online html program Limesurvey.

\section{The 24-h recalls}

To conduct the 24HRs, a structured interview guide was developed, with questions in a chronological order covering daily meal patterns including promt questions. Dietary intake reported by the participant was reported directly into a pre-coded Danish food record by the interviewer. The pre-coded Danish food record is a semi-closed questionnaire with answer categories for the most commonly consumed dishes according to meal patterns in Denmark as used in the nationally representative survey of Dietary Habits and Physical Activity (DANSDA) in 2011-2013 [27]. Open answers were available in each section if consumed foods were not found in the pre-coded categories. Household measures were used for quantification of portion sizes. After the interview, answers were reviewed orally together with the adolescent to make sure everything he/she had consumed was recorded.

\section{Calculation foods and nutrient intakes from the FFQ and the 24HRs}

Frequencies of intake were computed into grams per day using nutrition software Foodcalc v.3 [28]. Nutritional calculations for the FFQ were done based on assumptions of standard portion sizes. The 24HRs were entered into an online registration system (fa.kostvaner.dk, template by cmsimple-styles.com) developed at the Danish National Food Institute (Tue Christensen, personal communication). National food composition tables [29] were used for both the FFQ and the 24HRs.

\section{Statistics}

All statistical analyses were performed in the statistical program SAS version 9.4 (SAS Institute, Cary, NC, USA). Participant characteristics were evaluated using descriptive statistics. Age- and gender-specific cut-offs for overweight and obesity among the offspring were based on values provided by the International Obesity Task Force (IOTF) [30]. Parental educational level was retrieved from the maternal FFQ in the DNBC.

We presented median along with $25^{\text {th }}$ and $75^{\text {th }}$ percentile for food groups and nutrients since data were non-normally distributed both before and after logtransformation (except energy percent of macronutrients which were normally distributed). Paired t-test was used to compare differences between the two methods for normally distributed variables while Wilcoxon rank test was used for skewed variables. To compare differences in estimated intake between the two methods the median difference in percentages was calculated according to the formula: ((FFQ - 24HR)/24HR)*100. Misclassification analysis (into quantiles) including weighted Kappa was applied in order to test whether the FFQ ranked adolescents according to magnitude of dietary and nutrient intake by comparison to the mean of the three $24 \mathrm{HRs}$. It has been suggested that at least $50 \%$ of subjects should be classified into the same category, no more than $10 \%$ should be classified into the opposite category, and Cohen's weighted Kappa should preferably be above 0.4 [31]. Bland-Altman plots were used to elaborate whether the differences between the two methods were constant across the range of measurements, and mean intake was plotted against mean difference [32]. The association between food and nutrient intakes estimated with the two methods was assessed using crude, energy adjusted and de-attenuated Spearman's correlation coefficients. Correlation coefficients were adjusted using the ratio of withinand between-person variation assessed on the basis of the three 24HRs. These de-attenuated correlation coefficients should provide an estimate similar to that obtained with a higher number of 24HRs [9]. Adjustment for energy was performed with the residual method [9].

To estimate the degree of selection as a result of our recruitment strategy we compared characteristics of participants with those who did not wish to participate in the validation study (non-participants). Differences in characteristics of participants born to GDMmothers vs. other offspring participants were also compared. Finally, characteristics of our participants were compared with those in the full source population, i.e. the DNBC 14year follow-up study. For these comparisons we applied analysis of variance. 


\section{Results}

The mean age (SD) and body mass index (BMI) for the 124 participants were $13.2(0.7)$ years and $19.1 \mathrm{~kg} / \mathrm{m}^{2}$, respectively (Table 1 ). Among participants, $62 \%$ were born to GDMmothers, and $27.4 \%$ were overweight or obese (Table 1). The relative validity of the FFQ was evaluated by comparing estimated intake of food groups, energy and nutrients with the average of three 24HRs (Table 2). We found significant difference between the FFQ and the mean of three 24HRs for the majority of food groups. The food groups; fish, fruits, vegetables, and oils and dressing were overestimated by the FFQ when compared with the mean of three $24 \mathrm{HRs}$, whereas meat/poultry and sweets were underestimated by the FFQ. We found no significant difference for beverages, dairy, bread, and cereals. Median difference (\%) revealed the smallest differences for beverages $(+10 \%)$, bread $(-10 \%)$, and dairy $(-5 \%)$ and larger differences for fish $(+1000 \%)$, fruits $(+121 \%)$, and sweets $(-70 \%)$ (Table 2$)$.

For nutrients, there were no significant differences in total energy, polyunsaturated fatty acids (PUFA), energy percent (E\%) from carbohydrate, dietary fibres, calcium and iron. Protein $\mathrm{E} \%$ and vitamin $\mathrm{C}$ were overestimated, while the remaining nutrients were underestimated by the FFQ in comparison with the three 24HRs. The median differences (\%) showed smallest differences (or null for carbohydrate E\% and iron) for fat E\% (-3\%) and calcium $(-0.7)$, whereas the largest degree of under- or overestimation was seen for added sugar $(-36 \%)$ and vitamin $\mathrm{C}(+34 \%)$ (Table 2$)$.

Consistency between the two methods was also examined using Bland-Altman plots. These plots for beverages, dairy, meat/poultry, vitamin $\mathrm{C}$, and calcium

Table 1 Participant characteristics ( $n=124,52 \%$ girls)

\begin{tabular}{llll}
\hline & All & Girls & Boys \\
\hline Age, years (mean, SD) & $13.2(0.7)$ & $13.3(0.6)$ & $13.2(0.7)$ \\
Height, cm (mean, SD) & $165.9(8.3)$ & $164.7(7.9)$ & $167.4(8.5)$ \\
BMI $^{\mathrm{a}}\left(\mathrm{kg} / \mathrm{m}^{2}\right)$ (mean, SD) & $19.1(7.9)$ & $19.2(7.9)$ & $19.1(8.3)$ \\
Overweight $^{\mathrm{a}}(\%)$ & 13.7 & 15 & 12 \\
Obese $^{\mathrm{a}}(\%)$ & 13.7 & 12 & 15 \\
Born to GDM mothers $^{\mathrm{b}}(\%)$ & 62 & 57 & 68 \\
Parental educational level (\%) & & & \\
$\quad$ High level of education & 21 & 26 & 15 \\
$\quad$ Medium level of education & 32.5 & 29 & 36 \\
$\quad$ Skilled workers & 32.5 & 30 & 36 \\
Student & 0.8 & 1.5 & 0 \\
Unskilled & 12 & 14 & 11 \\
$\quad$ Unemployed & 0.8 & 0 & 1.8 \\
\hline
\end{tabular}

$B M I$ body mass index $=$ weight $(\mathrm{kg}) / \mathrm{height}(\mathrm{m})^{2} \mathrm{GDM}$ gestational diabetes mellitus

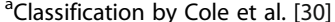

${ }^{\mathrm{b}}$ Adolescents born to mothers with registered gestational diabetes revealed some outliers, but no systematic patterns were observed (exemplified with dairy Fig. 1). For the remaining variables, the plots indicated a tendency towards higher difference between the FFQ and the $24 \mathrm{HRs}$ at higher mean intakes. This indicates a higher degree of overestimation and underestimation at higher intakes (exemplified with sweets Fig. 2). The mean difference in intake of e.g. sweets was below zero, confirming an underestimation by the FFQ. The pattern of observations indicated a higher degree of underestimation at higher mean intakes.

Misclassification (into the opposite quartile) was below $10 \%$ for all food groups and nutrients, except for fish and carbohydrate E\% (Table 2). Correct classification ranged from $23 \%$ (meat/poultry) to $46 \%$ (dairy), while nutrients ranged from 25\% (carbohydrate E\%) to 45\% (monounsaturated fatty acids (MUFA)). Weighted Kappa values ranged from 0.05 (meats/poultry) to 0.43 (dairy) (Table 2).

Spearman's correlation coefficients for food groups ranged from 0.03 (fish) to 0.60 (dairy). Three of the 10 food groups and 5 of the 12 nutrients examined had Spearman's correlations above 0.4. These were dairy, fruits, oils and dressing, saturated fatty acids (SFA), MUFA, PUFA, calcium, and iron (Table 3). For energy, the Spearman's correlation coefficient was 0.38 and the mean correlation coefficient for nutrients was 0.35 (Table 3). De-attenuation improved Spearman's correlation coefficients lightly for most variables, while further adjustment for energy only improved the correlation coefficients for MUFA (from 0.54 to 0.60) (Table 3).

The main reason given for not wishing to participate in this validation study (54 out of 178 invited) was lack of time. When we examined characteristics of participants $(n=124)$ and non-participants $(n=54)$, no substantial differences were found for sex, age, BMI, proportion born to GDM mothers, or parental education. Within our set of participants, we observed no significant differences in dietary intakes between offspring born to GDM and non-GDM mothers for all dietary variables tested except for vegetables (mean difference of: $25 \mathrm{~g} / \mathrm{d}$, highest among offspring born to GDM mothers) (data not shown). Overall, minor differences in dietary habits between overweight- and normal-weight participants were found: the mean difference between the FFQ and the $3 \times 24 \mathrm{HRs}$ was significantly higher for energy from protein $(1.3 \mathrm{E} \%)$ and significantly lower for carbohydrate $(-3.7 \mathrm{E} \%)$ among overweight children compared with normal weight children (Additional file 1: Table S1). Furthermore, comparing our study population in which GDMmothers are overrepresented (and not participating in the DNBC follow-up, $n=76$ ) with the adolescents from the DNBC 14-year follow-up $(n=$ 24,879 ) we found no significant difference for proportion 
Table 2 Relative validity: mean and median intake of food groups, energy and nutrients from FFQ and 3x24HR, percentage difference, and percentage agreement in categories $(n=124)$

\begin{tabular}{|c|c|c|c|c|c|c|c|c|}
\hline \multirow[b]{2}{*}{$\begin{array}{l}\text { Food groups (g/ } \\
\text { d) }\end{array}$} & \multicolumn{2}{|l|}{ FFQ } & \multicolumn{2}{|l|}{$3 \times 24 \mathrm{HR}$} & \multirow{2}{*}{$\begin{array}{l}\text { Median diff. } \\
\%\end{array}$} & \multicolumn{3}{|c|}{ Classification (\%) } \\
\hline & Median & $q^{1}-q^{3}$ & Median & $q_{1}-q^{3}$ & & $\begin{array}{l}\text { Same } \\
\text { quartile }\end{array}$ & $\begin{array}{l}\text { Opposite } \\
\text { quartile }\end{array}$ & $\begin{array}{l}\text { Weighted } \\
\text { Kappa }\end{array}$ \\
\hline Beverages & 1131 & $648-1273$ & 1032 & $821-1464$ & -10 & 35 & 9 & 0.20 \\
\hline Dairy & 319 & $182-636$ & 335 & $182-521$ & -4.7 & 46 & 6 & 0.43 \\
\hline Bread & 185 & 109-275 & 204 & $146-258$ & -9 & 28 & 7 & 0.12 \\
\hline Cereals & 27 & $14-50$ & 24 & $9-52$ & 12 & 35 & 6 & 0.25 \\
\hline Meats/poultry & $82^{*}$ & $56-118$ & 107 & 69-139 & -23 & 23 & 7 & 0.05 \\
\hline Fish & $11^{*}$ & $6-18$ & 1 & $0-16$ & 1000 & 32 & 18 & n.a. \\
\hline Fruits & $126^{* *}$ & $52-247$ & 57 & 9-135 & 121 & 43 & 6 & 0.32 \\
\hline Vegetables & $116^{*}$ & $65-171$ & 91 & $62-130$ & 27 & 32 & 9 & 0.12 \\
\hline Sweets & $17^{* *}$ & $10-28$ & 57 & 24-108 & -70 & 33 & 4 & 0.20 \\
\hline Oils \& dressing & $36^{*}$ & $22-47$ & 26 & $18-51$ & 38 & 38 & 3 & 0.32 \\
\hline Nutrients & $\begin{array}{l}\text { Mean or } \\
\text { Median }\end{array}$ & $\begin{array}{l}\text { SD or q1- } \\
\text { q3 }\end{array}$ & $\begin{array}{l}\text { Mean or } \\
\text { Median }\end{array}$ & $\begin{array}{l}\text { SD or q1- } \\
\text { q3 }\end{array}$ & & & & \\
\hline Energy (MJ/d) & 7.6 & $5.7-9.7$ & 8.5 & $7.0-11.0$ & -10 & 36 & 5 & 0.26 \\
\hline Protein (E\%) & $15^{* *}$ & 2.7 & 13 & 2.5 & 15 & 37 & 6 & 0.24 \\
\hline Fat (E\%) & $34^{*}$ & 6.3 & 35 & 6.0 & -3 & 34 & 8 & 0.24 \\
\hline SFA (g/d) & $26^{* *}$ & $19-33$ & 33 & $23-44$ & -21 & 40 & 2 & 0.34 \\
\hline MUFA (g/d) & $24^{*}$ & $16-31$ & 27 & $20-36$ & -11 & 45 & 2 & 0.39 \\
\hline PUFA (g/d) & 12 & $8-15$ & 11 & $9-15$ & 9 & 36 & 3 & 0.29 \\
\hline $\begin{array}{l}\text { Carbohydrate } \\
(\mathrm{E} \%)\end{array}$ & 51 & 6.5 & 51 & 6.0 & 0 & 25 & 14 & 0.10 \\
\hline Added sugar (g/d) & $26^{* *}$ & $15-38$ & 41 & $25-69$ & -36 & 31 & 5 & 0.23 \\
\hline Dietary fiber (g/d) & 21 & $15-32$ & 18 & $15-24$ & 16 & 41 & 5 & 0.30 \\
\hline Vitamin C (mg/d) & $66^{* *}$ & $43-100$ & 49 & $33-69$ & 34 & 31 & 7 & 0.14 \\
\hline Calcium (mg/d) & 867 & $647-1374$ & 873 & $672-1229$ & -0.7 & 39 & 6 & 0.33 \\
\hline Iron (mg/d) & 8.3 & $6.3-12.5$ & 8.3 & $6.7-10.8$ & 0 & 40 & 4 & 0.29 \\
\hline
\end{tabular}

Variables that reached normality after log-transformation were beverages, dairy, bread, oils \& dressing, energy, SFA, MUFA, PUFA, added sugar, dietary fibers, vitamin C, calcium and iron whereas cereals, meat/poultry, fish, fruit, vegetables and sweets did not reach normality after log-transformation Median difference in percent $=$ median $(\mathrm{FFQ}-24 \mathrm{HR} / 24 \mathrm{HR}) * 100$

FFQ food frequency questionnaire, $24 H R, 24-\mathrm{h}$ recalls, SFA saturated fatty acids, MUFA monounsaturated fatty acids, PUFA polyunsaturated fatty acids ${ }^{*} p<0.05$ significantly different from $24 \mathrm{HR}$

$*^{* *} p<0.001$ significantly different from $24 \mathrm{HR}$

of girls $(47 \%$ vs. $52 \%, p=0.10)$, parental education $(p=$ $0.11)$, and maternal smoking $(p=0.13)$. However, children in the validation study were significantly younger (7 months, $p<0.0001$ ), and were more frequently overweight/obese $(16 \%$ vs. $9 \%, p=0.03)$ compared with the adolescents from the DNBC 14-year follow-up. No significant differences in nutrient intake on a group level were observed across the three 24HRs (data not shown).

\section{Discussion}

Comparing dietary intake assessed by the web-based FFQ with that of three 24HRs among Danish adolescents we found that four (fish, fruits, vegetables, and oils and dressing) out of 10 food groups and three (protein
$\mathrm{E} \%$, dietary fibres, and vitamin $\mathrm{C}$ ) of the 11 nutrients were overestimated by the FFQ. This is similar to what has often been reported in similar studies in adolescents $[13,33,34]$. Total energy intake did not differ significantly between the two methods which is comparable to what was found in the validation study of the original GUTS questionnaire [13]. However, in the validation study by Rockett et al. mean Pearson correlation coefficients for nutrients were 0.41 compared with 0.35 in our study (Spearman's correlation coefficients). Even though the agreement estimated by the kappa statistics primarily was poor to fair/moderate (ranging from 0.05-0.43 [35]), the ability to rank adolescents according to magnitude of intake was good in the sense that 


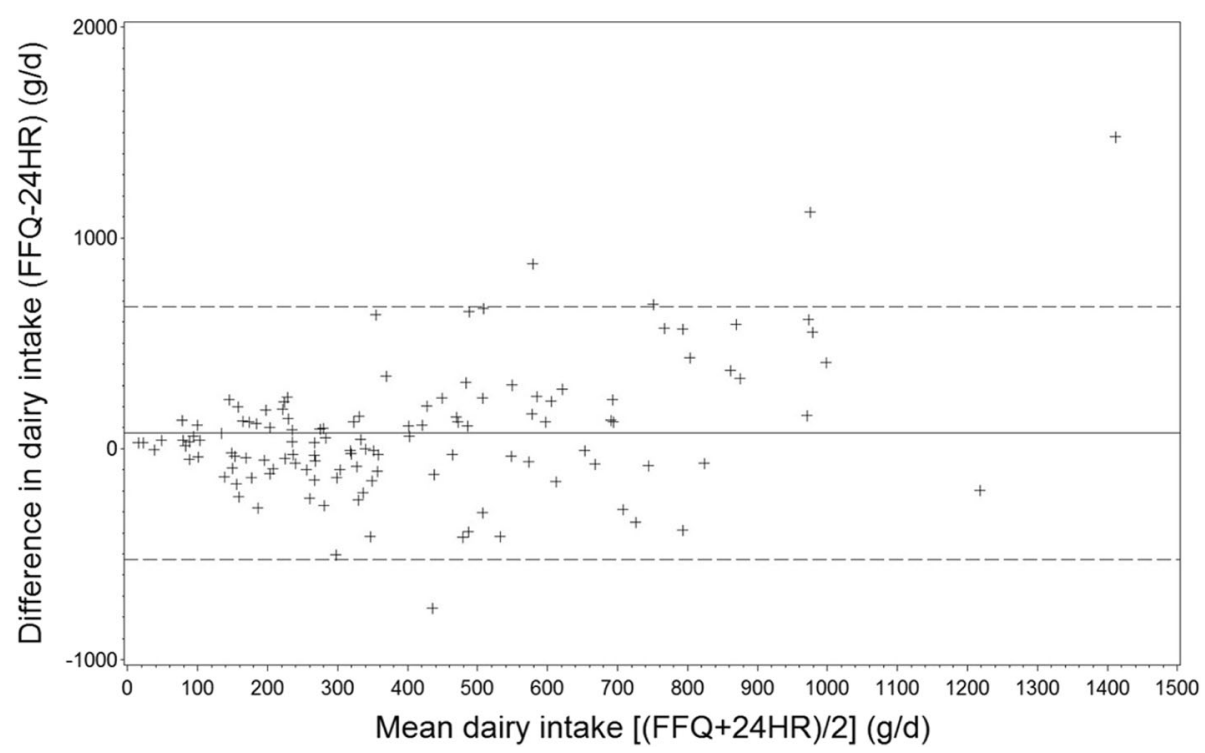

Fig. 1 Bland-Altman plot for dairy intake for the two methods FFQ and mean of three 24HR among participants $(n=124)$. The difference in intake is plottet $v$. the mean intake from the two methods._—_ represents the mean difference ——— represents the $95 \%$ limits of agreement

misclassification (in the opposite quartile) below 10\% was seen for most food groups and nutrients, except for fish and carbohydrate E\% [31]. Misclassification below $5 \%$ was seen for oils and dressing, fatty acids, and iron.

When comparing our results with a validation study performed using a similar FFQ to ours in the Norwegian mother-child cohort, we found a lower level of misclassification into opposite quartile in general. However, it must be noted that the Norwegian study used quintiles [12].
Intake of fish, fruits, and sweets differed significantly between the two methods, with higher intake of fruits and fish and lower intake of sweets in the FFQ relative to the 24HRs. Fish is often rarely consumed and may not be captured by only 3 days of dietary recording, as was also observed in other studies [12]. Even though the three randomly assigned $24 \mathrm{HRs}$ covered all 7 weekdays, three 24HRs might not have sufficiently estimated the day-to-day variability [9] of e.g. fish, resulting in large median difference and low correlation between the two

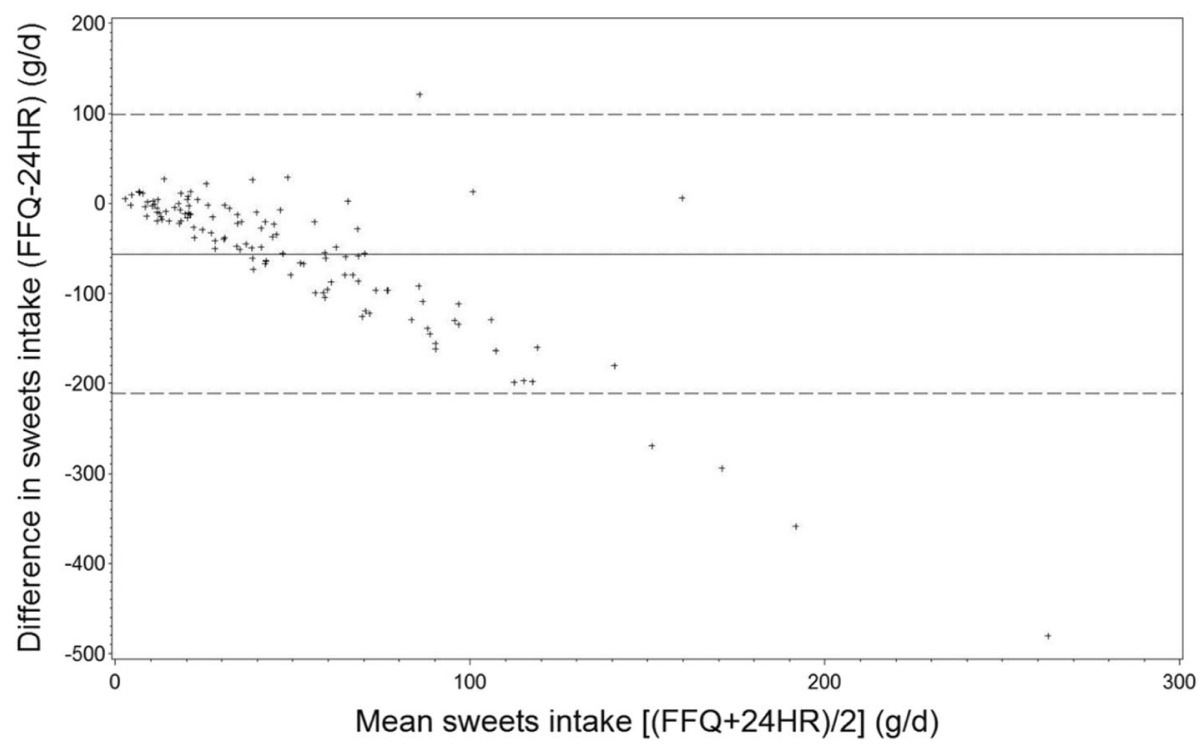

Fig. 2 Bland-Altman plot for sweets intake for the two methods FFQ and mean of three $24 \mathrm{HR}$ among participants $(n=124)$. The difference in intake is plottet $v$. the mean intake from the two methods.__ represents the mean difference __ _ represents the $95 \%$ limits of agreement 
Table 3 Spearman correlation coefficient between FFQ and 3x24HR $(n=124)$

\begin{tabular}{|c|c|c|c|}
\hline \multirow[b]{2}{*}{ Food groups (g/d) } & \multicolumn{3}{|c|}{ Spearman correlation coefficients $r$} \\
\hline & crude & De-attenuated & Energy adjusted \& de-attenuated \\
\hline Beverages & $0.22^{*}$ & $0.24^{*}$ & $0.24^{*}$ \\
\hline Dairy & $0.60^{* *}$ & $0.69^{* *}$ & $0.61^{* *}$ \\
\hline Bread & $0.19^{*}$ & $0.19^{*}$ & $0.19^{*}$ \\
\hline Cereals & $0.33^{*}$ & $0.35^{*}$ & $0.35^{*}$ \\
\hline Meats/poultry & 0.16 & 0.17 & 0.16 \\
\hline Fish & 0.03 & 0.03 & 0.03 \\
\hline Fruits & $0.40^{* *}$ & $0.43^{* *}$ & $0.41^{* *}$ \\
\hline Vegetables & 0.13 & 0.13 & 0.13 \\
\hline Sweets & $0.31^{*}$ & $0.32^{*}$ & $0.31^{*}$ \\
\hline Oils \& dressing & $0.46^{* *}$ & $0.48^{* *}$ & $0.47^{* *}$ \\
\hline \multicolumn{4}{|l|}{ Nutrients } \\
\hline Energy (MJ/d) & $0.38^{* *}$ & $0.54^{* *}$ & \\
\hline Protein (E\%) & 0.28 & 0.32 & \\
\hline Fat (E\%) & $0.27^{*}$ & $0.28^{*}$ & \\
\hline SFA (g/d) & $0.51^{* *}$ & $0.54^{* *}$ & $0.53^{* *}$ \\
\hline MUFA (g/d) & $0.52^{* *}$ & $0.54^{* *}$ & $0.60^{* *}$ \\
\hline PUFA (g/d) & $0.47^{* *}$ & $0.48^{* *}$ & $0.47^{* *}$ \\
\hline Carbohydrate (E\%) & 0.09 & 0.09 & \\
\hline Added sugar (g/d) & $0.37^{* *}$ & $0.38^{* *}$ & $0.39^{* *}$ \\
\hline Dietary fiber (g/d) & $0.32^{*}$ & $0.33^{*}$ & $0.33^{*}$ \\
\hline Vitamin C (mg/d) & $0.21^{*}$ & $0.22^{*}$ & $0.22^{*}$ \\
\hline Calcium m(g/d) & $0.46^{* *}$ & $0.51^{* *}$ & $0.51^{* *}$ \\
\hline Iron (g/d) & $0.40^{*}$ & $0^{*} .41$ & $0.41^{*}$ \\
\hline
\end{tabular}

De-attenuated, correlation coefficients adjusted for within-person variation using ANOVA to estimate within- and between-person variance and ratio ${ }^{*} p<0.05$, significant Spearman correlation

${ }^{* *} p<0.001$, significant Spearman correlation

methods. Further, a high number of subjects were misclassified in the opposite quartile of intake which was also observed in the study by Overby et al. [12]. According to a Danish study using dietary data from The Danish National Survey of Dietary Habits and Physical Activity 2003-2008, intake of sweets, cakes, and sugar-sweetened beverages among 789 children aged 4-14 years were higher during weekends compared with weekdays [36]. Together with the fact that adolescents were found to be more prone to omit foods compared with adults [19], the lower estimated intake of sweets in the FFQ might be a result of intake during weekends being omitted by the adolescents when completing the FFQ.

The percentage difference in intake between the FFQ and $3 \times 24$ HRs of $121 \%$ for fruits (highest in the FFQ) and a correlation coefficient of 0.13 for vegetables deserves some attention. A relatively large intervention study among 9-10year-old Danish children $(n=798)$ reported a median (p10, p90) intake of fruits of $126 \mathrm{~g} / \mathrm{d}(38,244)$ and a median (p10, p90) intake of vegetables of $126 \mathrm{~g} / \mathrm{d}(54,227)$ measured by $7 \mathrm{~d}$ food records [37]. The level of intake is comparable to the median (p25, p75) intake of fruits estimated with our FFQ; 126 g/d (52-247). Additionally, the Danish study showed a significantly higher consumption during school hours compared with outside school [37]. Further, a study among 96 adolescents aged 11 to 15 years found only $30 \%$ match between a $24 \mathrm{HR}$ method and direct observations [38]. Therefore, it could be speculated that meals consumed during school hours were omitted during $24 \mathrm{HRs}$ and fruits and vegetables were underestimated by the 24HRs. However, since prompt questions were included in the 24HRs to ensure that intake during school hours was captured, intake of fruits may have been overestimated by the FFQ as a consequence of a high number of questions about fruits in the FFQ. Variation in season should, furthermore, also be considered. The FFQ was completed from December to March whereas the 24HRs were conducted between January and June. Thus, there were some overlapping periods at group level. If season had had a substantial impact, we would have expected higher intakes of fruits 
and vegetables estimated from the 24HRs in the spring. However, median intakes of fruits and vegetables were lower in the 24HRs compared with the FFQ.

The observed disparities in mean intakes of food groups and low percentages classified into same quartile were to some extent expected due to the adolescent study population. Adolescents are known to pay less attention to dietary habits, and their snacking and eating habits tend to be more unstructured compared with those of adults. They may also be less motivated to record their dietary intake and have increased focus on body image, which seems to affect the accuracy of their self-report [39]. These characteristics may result in high within-person day-to-day variability among adolescents which seems to attenuate correlation coefficients $[9,14]$. This was in particular evident for dairy, energy intake, MUFA, and calcium where Spearman's correlation coefficient increased after de-attenuation which was also reported in the study by Rockett et al. [13]. However, Spearman's correlation coefficients for bread, fish and carbohydrate E\% did not improve after de-attenuation. This suggests that intake of bread and fish was reported consistently over time, whereas other intakes varied more among the participating adolescents. De-attenuation improved an already strong correlation coefficient for dairy, indicating some variation between days nevertheless; recall of milk products was rather constant. Studies have reported that adolescents might have some difficulties in combining amount of foods eaten and frequency [18] which could also have contributed to the observed level of inconsistencies across foods and nutrients.

Energy adjustment did not affect level of correlation coefficients substantially in any direction, indicating that intake was not related to systematic errors of under- or over estimation of intake, nor was nutrient intake related to energy intake [9]. Difficulties in reaching strong correlation coefficients among adolescents were presented in a systematic review where only 2 of the 18 validity studies reported mean correlation coefficients above 0.50 [40]. Recall periods of 1 day or 1 week and fewer than 70 food items in the FFQ were assigned as main reasons for stronger correlation coefficients [40]. However, in a recent meta-analysis by Tabacchi et al., correlation coefficients for most nutrients in 16 validity studies were above 0.40 , and it was suggested that the number of food items should not exceed 114 [10]. We cannot rule out that the number of food items in our FFQ (145) could be a contributor to the observed overestimation of some food groups. However, the correlation coefficient of e.g. fruits was 0.40. Nonetheless, both similar and stronger correlation coefficients ranging from $\sim 0$ to 0.8 have been reported for nutrients and food groups in other validation studies among adolescents $[12,14,34]$. Also in adults, higher correlation coefficients have been observed [41, 42] which could be due to better skills in frequency estimation, better memory of consumed foods, and better knowledge to identify foods compared with those of children [18]. This was to some extent confirmed in a study among 11- to 15-yearold children accordingly to which unfamiliar food terms, unfamiliar measurements, and poor knowledge of food fractions made recording diet problematic using a webbased 24HR [38]. Training of recalling diet among children has previously been suggested by $\mathrm{Lu}$ and colleagues in order to improve accuracy [43]. It could therefore be speculated whether training in recalling diet before the actual dietary assessment with an FFQ could increase both motivation and food knowledge among the adolescent population and thereby improve the quality of the results.

This validation study has several strengths. The webbased FFQ was easy to administer and it may increase participant motivation that recording takes less than $1 \mathrm{~h}$, thereby potentially increasing participation rate [44]. The time interval of 4 weeks between the FFQ and the 24HRs seemed adequate to avoid carryover effects from the FFQ to the 24HRs [45]. Three non-consecutive 24HRs were chosen as reference method, because these have been suggested to be sufficient to assess habitual energy intake [46]. Since adolescents seem to have high within-person variation in diet, de-attenuated correlation coefficients were calculated in order to obtain an estimate similar to that gained with a higher number of 24HRs [9]. We ensured high quality of the 24HRs with four trained project team members conducting the interviews. Recalls by telephone have shown to yield results similar to those of face-to-face interviews [47]. Moreover, this method was less expensive and we were able to reach participants from across the country [48]. Furthermore, telephone interviews potentially decreased the correlation between the test and reference method [49]. With the allocation of interview days, we secured representation of all weekdays at group level. Nevertheless, due to adolescents' eating habits, some food items might not have been captured sufficiently. When we report correlation coefficients between the FFQ and the three 24HRs that rely on individual responses to these assessments, the number of days are not equally distributed between study participants. Since the days were randomly allocated this should not bias our estimates.

Limitations of the present study are firstly the different recall periods of the FFQ and the 24HRs. This could potentially increase the differences in observed estimates, as the FFQ was a self-administered long-term recall compared with the interview-based prompted shortterm 24HR. Secondly, the 12-15-year age range of both boys and girls may have contributed to the relatively large variability within the study population and thus 
overall have lowered the level of relative validity. Thirdly, the FFQ and 24HR methods share measurement errors, e.g. both methods rely on memory [50]. Therefore, more objective measures, though also subject to measurement errors, such as observations in school or the double labelled water method, could have added an objective validation perspective of the FFQ tested. Finally, the fact that cohorts are often oversampled with a higher level of socio-economic status, and that $62 \%$ of the present study population were born to GDMmothers may render the results of the present study less representative for the Danish adolescent population with respect to e.g. proportion of overweight/obese adolescents [51, 52]. However, comparisons between our participants and the entire DNBC cohort of 14-year-olds (currently participated $n=24,879)$ revealed relatively minor differences. In these analyses, the difference in age was relatively small and is due to the recruitment of children younger than 14 years of age, which was necessary to increase sample size in the validation study.

\section{Conclusion}

The relative validity of the FFQ compared with the $3 \times 24$ HRs showed that the ranking ability differed across food groups and nutrients. When considering the classification in quartiles and the Spearman's correlation coefficients together, the relative validity showed that the ranking ability was acceptable for estimated intake of dairy, fruits, oils and dressing, SFA, MUFA and iron. No major misclassification was observed for oils and dressings and fatty acids. Larger variation was seen for fish, sweets, and vegetables, and caution should be taken when interpreting estimation from the FFQ of fish and carbohydrate $\mathrm{E} \%$. When evaluating estimates from the web-based FFQ among Danish adolescents these findings should be considered.

\section{Additional file}

Additional file 1: Table S1. Mean intake of food groups, energy and nutrients from FFQ and 3×24HR stratified by BMl categories. (DOCX $14 \mathrm{~kb}$ )

\section{Abbreviations}

24HRs: 24-h recalls; BMI: Body Mass Index; DNBC: Danish national birth cohort; E\%: Energy percent; FFQ: Food frequency questionnaire; GDM: Gestational diabetes mellitus; GUTS: Growing up today study: GW: Gestation week; IOTF: International obesity task force; MUFA: Monounsaturated fatty acids; NHS II: Nurses' health study II; PUFA: Polyunsaturated fatty acids; SD: Standard deviation; SFA: Saturated fatty acids; YAQ: Youth/ adolescent questionnaire

\section{Acknowledgments}

The authors would like to thank senior researcher Tue Christensen, National Food Institute, Technical University of Denmark, for providing access to the precoded Danish food record, introduction to the program used for entering dietary recalls, and for supervision in data handling. We also want to thank dietician Karin Hess Ygil, National Food Institute, Technical University of Denmark, for helpful support in interpretating of the dietary recalls. Finally, many thanks to BSc students Nynne Dose, Maria Wichmann and Samiha El Halimi for professional data collection and to Samiha El Halimi for detailed check during data entry. The Danish Diabetes Academy is supported by the Novo Nordisk Foundation.

\section{Funding}

The study was supported by grants from The Danish Research Council 09067124 (Center for Fetal Programming), 09-075611; and the Intramural Research Program of The Eunice Kennedy Shriver National Institute of Child Health and Human Development, National Institutes of Health (contract \# HHSN275201000020C). The funding bodies had no role in the design of the study, collection, analysis, interpretation of data or in writing the manuscript.

\section{Availability of data and materials}

The datasets used and analysed during the current study are available from the corresponding author on reasonable request.

\section{Authors' contributions}

SFO initiated the validation study and secured funding for it. In coorperation, all authors formulated the research question and design of the study. $A A B$ was responsible for carrying out the study, analysing the data and writing the article. TIH assisted in analysing the data. TIH, FBK and IT assisted interpreting the data and writing the article. TIH, FBK, SFO, and IT critically reviewed the manuscript and all co-authors approved the final version submitted.

\section{Ethics approval and consent to participate}

This study was conducted according to the guidelines laid down in the Declaration of Helsinki and all procedures involving human subjects were approved by the National Committee on Health Research Ethics in 57 Denmark (H-4-2011-045). Written informed consent was obtained from all subjects.

\section{Consent for publication}

Not applicable

\section{Competing interests}

The authors declare that they have no competing interests.

\section{Publisher's Note}

Springer Nature remains neutral with regard to jurisdictional claims in published maps and institutional affiliations.

\section{Author details}

${ }^{1}$ Center for Fetal Programming, Department of Epidemiology Research, Statens Serum Institut, Artillerivej 5, 2300 Copenhagen, Denmark. ${ }^{2}$ The Unit for Nutrition Research, Faculty of Food Science and Nutrition, School of Health Sciences, University of Iceland, Sæmundargata 2, 101 Reykjavík, Iceland. ${ }^{3}$ Division for Diet, Disease Prevention and Toxicology, National Food Institute, Technical University of Denmark, DTU Food, Kemitorvet, building, 202 Kgs. Lyngby, Denmark. ${ }^{4}$ Department of Endocrinology, Diabetes and Metabolism, Rigshospitalet, Copenhagen, Denmark. ${ }^{5}$ The Danish Diabetes Academy, Odense, Denmark. ${ }^{6}$ Vitality - Centre for Good Older Lives, Department of Nutrition, Exercise, and Sports, University of Copenhagen, University of Copenhagen, Rolighedsvej 26, 1958 Frederiksberg C, Denmark.

Received: 20 March 2017 Accepted: 2 January 2018

Published online: 12 January 2018

References

1. Prentice A, Schoenmakers I, Laskey MA, de Bono S, Ginty F, Goldberg GR. Nutrition and bone growth and development. Proc Nutr Soc. 006;65(4):348-60.

2. Lipsky LM, Haynie DL, Liu D, Chaurasia A, Gee B, Li K, et al. Trajectories of eating behaviors in a nationally representative cohort of U.S. adolescents during the transition to young adulthood. Int J Behav Nutr Phys Act. 2015;12:138.

3. Berkey CS, Willett WC, Tamimi RM, Rosner B, Frazier AL, Colditz GA. Vegetable protein and vegetable fat intakes in pre-adolescent and adolescent girls, and risk for benign breast disease in young women. Breast Cancer Res Treat. 2013;141(2):299-306. 
4. Wiium N, Breivik K, Wold B. Growth trajectories of health behaviors from adolescence through young adulthood. Int J Environ Res Public Health. 2015;12(11):13711-29.

5. Vereecken CA, Maes L. A Belgian study on the reliability and relative validity of the health behaviour in school-aged children food-frequency questionnaire. Public Health Nutr. 2003:6(6):581-8.

6. Truthmann J, Mensink GB, Richter A. Relative validation of the KiGGS food frequency questionnaire among adolescents in Germany. Nutr J. 2011;10:133.

7. Subar AF. Developing dietary assessment tools. J Am Diet Assoc. 2004;104(5):769-70.

8. Beaton $\mathrm{GH}$. Approaches to analysis of dietary data: relationship between planned analyses and choice of methodology. Am J Clin Nutr. 1994:59(1 Suppl):253s-61s.

9. Willett WC. Nutritional epidemiology. 2nd ed. New York: Oxford University Press; 1998.

10. Tabacchi G, Amodio E, Di Pasquale M, Bianco A, Jemni M, Mammina C. Validation and reproducibility of dietary assessment methods in adolescents: a systematic literature review. Public Health Nutr. 2014;17(12):2700-14.

11. Hong TK, Dibley MJ, Sibbritt D. Validity and reliability of an FFQ for use with adolescents in ho chi Minh City, Vietnam. Public Health Nutr. 2010;13(3):368-75.

12. Overby NC, Johannesen E, Jensen G, Skjaevesland AK, Haugen M. Test-retest reliability and validity of a web-based food-frequency questionnaire for adolescents aged 13-14 to be used in the Norwegian mother and child cohort study (MoBa). Food NutrRes. 2014;58:23956.

13. Rockett $H R$, Breitenbach M, Frazier AL, Witschi J, Wolf AM, Field AE, et al. Validation of a youth/adolescent food frequency questionnaire. PrevMed. 1997;26(6):808-16

14. Martinez MF, Philippi ST, Estima C, Leal G. Validity and reproducibility of a food frequency questionnaire to assess food group intake in adolescents. Cadernos de saude publica. 2013;29(9):1795-804.

15. Cade JE, Burley VJ, Warm DL, Thompson RL, Margetts BM. Food-frequency questionnaires: a review of their design, validation and utilisation. Nutr Res Rev. 2004;17(1):5-22

16. De Moor C, Baranowski T, Cullen KW, Nicklas T. Misclassification associated with measurement error in the assessment of dietary intake. Public Health Nutr. 2003;6(4):393-9.

17. Chambers E, Godwin SL, Vecchio FA. Cognitive strategies for reporting portion sizes using dietary recall procedures. J Am Diet Assoc. 2000;100(8):891-7.

18. Livingstone MB, Robson PJ. Measurement of dietary intake in children. Proc Nutr Soc. 2000;59(2):279-93.

19. Lyng N, Fagt S, Davidsen M, Hoppe C, Holstein B, Tetens I. Reporting accuracy of packed lunch consumption among Danish 11-year-olds differ by gender. Food Nutr Res. 2013;57

20. Olsen SF, Mikkelsen TB, Knudsen VK, Orozova-Bekkevold I, Halldorsson TI Strom M, et al. Data collected on maternal dietary exposures in the Danish National Birth Cohort. Paediatr Perinat Epidemiol. 2007;21(1):76-86.

21. Zhang C, Hu FB, Olsen SF, Vaag A, Gore-Langton R, Chavarro JE, et al. Rationale, design, and method of the Diabetes \& Women's health study-a study of long-term health implications of glucose intolerance in pregnancy and their determinants. Acta Obstet Gynecol Scand. 2014;93(11):1123-30.

22. GUTS. Growning Up Today Study. http://www.gutsweb.org/. Assessed April 2014

23. Fagt S, Matthiessen J, Trolle E, Lyhne N, Christensen T, Hinsch H-J, et al. 2. Danskernes kostvaner 2000-2001. Udviklingen i danskernes kost - forbrug, indkøb og vaner. Fødevaredirektoratet; 2002. Available from: http://www. food.dtu.dk/publikationer/ernaering-og-kostvaner

24. Fagt S, Christensen T, Groth MV, Biltoft-Jensen A, Matthiessen J, Trolle E. Børn og unges måltidsvaner 2000-2004 (dietary patterns of Danish children and adolescents 2000-2004): Fødevareinstituttet, DTU; 2007. Available from: http://www.food.dtu.dk/publikationer/ernaering-og-kostvaner

25. Bjerregaard AA, Tetens I, Olsen SF, Halldorsson TI. Reproducibility of a webbased FFQ for 13- to 15-year-old Danish adolescents. Journal of nutritional science. 2016:5:e5

26. Ygil KH. Mål, vægt og portionsstørrelser (Dimensions, Weight and Portion sizes of Foods). Søborg: Fødevareinstituttet, DTU; 2013.

27. Pedersen AN, Christensen T, Matthiessen J, Knudsen VK, Rosenlund-Sørensen M, Biltoft-Jensen A, Hinsch HJ, Ygil KY, Kørup K, Saxholt E, Trolle E, Søndergaard AB, Fagt S. Dietary habits in Denmark 2011-2013. Main results. Report. Søborg. Denmark: National Food Institute; 2015. Available from: http://orbit.dtu.dk/files/ 110628064/Rapport_Danskernes_Kostvaner_2011_2013.pdf

28. Lauritsen J. Foodcalc v.1.3 http://www.ibt.ku.dk/jesper/foodcalc/ Assessed April 2014.
29. Danish Food Composition Data version www.foodcomp.dk. Assessed May 2015.

30. Cole TJ, Bellizzi MC, Flegal KM, Dietz WH. Establishing a standard definition for child overweight and obesity worldwide: international survey. BMJ. 2000;320(7244):1240-3.

31. Masson LF, McNeill G, Tomany JO, Simpson JA, Peace HS, Wei L, et al. Statistical approaches for assessing the relative validity of a food-frequency questionnaire: use of correlation coefficients and the kappa statistic. Public Health Nutr. 2003;6(3):313-21.

32. Bland JM, Altman DG. Measuring agreement in method comparison studies. Stat Methods Med Res. 1999;8(2):135-60.

33. Xia W, Sun C, Zhang L, Zhang X, Wang J, Wang H, et al. Reproducibility and relative validity of a food frequency questionnaire developed for female adolescents in Suihua, North China. PLoS One. 2011;6(5):e19656.

34. Henn RL, Fuchs SC, Moreira LB, Fuchs FD. Development and validation of a food frequency questionnaire (FFO-Porto Alegre) for adolescent, adult and elderly populations from southern Brazil. CadSaude Publica. 2010;26(11):2068-79.

35. Viera AJ, Garrett JM. Understanding interobserver agreement: the kappa statistic. Family Med. 2005;37(5):360-3.

36. Rothausen BW, Matthiessen J, Hoppe C, Brockhoff PB, Andersen LF, Tetens I. Differences in Danish children's diet quality on weekdays v. Weekend days. Public Health Nutr. 2012;15(9):1653-60.

37. Andersen R, Biltoft-Jensen A, Christensen T, Andersen EW, Ege M, Thorsen AV, et al. What do Danish children eat, and does the diet meet the recommendations? Baseline data from the OPUS school meal study. J Nutr Sci. 2015;4:e29.

38. Krehbiel CF, DuPaul GJ, Hoffman JA. A validation study of the automated self-administered 24-hour dietary recall for children, 2014 version, at school lunch. J Acad Nutr Diet. 2017;117(5):715-24.

39. Bandini LG, Schoeller DA, Cyr HN, Dietz WH. Validity of reported energy intake in obese and nonobese adolescents. Am J Clin Nutr. 1990;52(3):421-5.

40. Kolodziejczyk JK, Merchant G, Norman GJ. Reliability and validity of child/ adolescent food frequency questionnaires that assess foods and/or food groups. J Pediat Gastroenterol Nutr. 2012;55(1):4-13.

41. Johansson I, Hallmans G, Wikman A, Biessy C, Riboli E, Kaaks R. Validation and calibration of food-frequency questionnaire measurements in the northern Sweden health and disease cohort. Public Health Nutr. 2002:5(3):487-96.

42. Haftenberger M, Heuer T, Heidemann C, Kube F, Krems C, Mensink GB. Relative validation of a food frequency questionnaire for national health and nutrition monitoring. Nutr J. 2010;9:36.

43. Lu AS, Baranowski J, Islam N, Baranowski T. How to engage children in self-administered dietary assessment programmes. J Hum Nutr Diet. 2014;27(Suppl 1):5-9.

44. Boushey CJ, Kerr DA, Wright J, Lutes KD, Ebert DS, Delp EJ. Use of technology in children's dietary assessment. Eur J Clin Nutr. 2009;63(Suppl 1):S50-7.

45. Deschamps V, de Lauzon-Guillain B, Lafay L, Borys JM, Charles MA, Romon M. Reproducibility and relative validity of a food-frequency questionnaire among French adults and adolescents. Eur J Clin Nutr. 2009;63(2):282-91.

46. Ma Y, Olendzki BC, Pagoto SL, Hurley TG, Magner RP, Ockene IS, et al. Number of 24-hour diet recalls needed to estimate energy intake. Ann Epidemiol. 2009;19(8):553-9.

47. Casey PH, Goolsby SL, Lensing SY, Perloff BP, Bogle ML. The use of telephone interview methodology to obtain 24-hour dietary recalls. J Am Diet Assoc. 1999;99(11):1406-11.

48. Fox TA, Heimendinger J, Block G. Telephone surveys as a method for obtaining dietary information: a review. J Am Diet Assoc. 1992;92(6):729-32.

49. Serra-Majem L, Pfrimer K, Doreste-Alonso J, Ribas-Barba L, Sanchez-Villegas A, Ortiz-Andrellucchi A, et al. Dietary assessment methods for intakes of iron, calcium, selenium, zinc and iodine. Br J Nutr. 2009;102(Suppl 1):S38-55.

50. Nelson M. The validtaion of dietary assessment. In: Margetts BMN, M., editor Design concepts in nutritional epidemiology. Second ed. Oxford Scholarship Online 2009

51. Molgaard C, Dele F, Froberg K, Heitman BL, Holm L, Madsen SA, et al. Forebyggelse af overvægt blandt børn og unge - oplæg til strategi. (Prevention of Obesity Among Children and Adolescents - Proposal for a Strategy) Motions- og Ernæringsrådet; 2007. Available from: https://www.sst. dk/publ/MER/2007/FOREBYGGELSE_AF_OVERVAEGT_BLANDT_BOERN_OG UNGE2007.PDF

52. Sundhedsstyrelsen. Opsporing af overvægt og tidlig indsats for børn og unge i skolealderen. 2014 2014. Copenhagen: Recognition of Overweight and Early Intervention for School-age Children; 2014. Available from: https:// www.sst.dk/da/udgivelser/2014/ /media/F7C0D97FB5F840C69CE9388 A0BAB4E1B.ashx 